\section{A INFLUÊNCIA DOS DIREITOS DE TRANSMISSÃO NO JORNALISMO ESPORTIVO: UM ESTUDO COM JORNALISTAS SOBRE A COBERTURA DOS JOGOS PARALÍMPICOS RIO/2016}

\author{
THE INFLUENCE OF BROADCASTING RIGHTS ON SPORTS \\ JOURNALISM: A STUDY CONDUCTED WITH JOURNALISTS ON THE \\ COVERAGE OF THE RIO/2016 PARALYMPIC GAMES
}

\section{LA INFLUENCIA DE LOS DERECHOS DE TRANSMISIÓN EN EL PERIODISMO DEPORTIVO: UN ESTUDIO CON PERIODISTAS SOBRE LA COBERTURA DE LOS JUEGOS PARALÍMPICOS RIO/2016}

\author{
Silvan Menezes dos Santos*, Josep Solves Almela**, \\ Doralice Lange de Souza
}

\begin{abstract}
Palavras chave:
Esportes.

Meios de

comunicação de

massa.

Jornalismo

Resumo: O objetivo da investigação foi caracterizar influências da detenção dos direitos de imagem e transmissão no processo de produção de notícias sobre os Jogos Paralímpicos Rio/2016. Esta pesquisa foi de cunho qualitativo, descritivo, exploratório e se inspirou em algumas características dos estudos de newsmaking. Entrevistamos 15 jornalistas e editores de diferentes grupos de mídia e jornais do país que cobriram o megaevento esportivo. As definições e delimitações do fazer jornalístico pautadas pelas questões comerciais, como por exemplo os limites de tempo e espaço para entrevistar os atletas e a dificuldade de, por vezes, eles acessarem ídolos esportivos regionais para a cobertura noticiosa direcionada a localidades específicas, indicam que, quando não se possui os direitos de transmissão, se restringe a amplitude e a complexidade das informações a serem recolhidas pelos jornalistas para a produção das notícias.
\end{abstract}

Keywords:

Sports.

Mass media.

Journalism

Palabras clave:

Deportes.

Medios de

comunicación

de masas.

Periodismo

Abstract: This study characterized influences of image and broadcasting rights on the process of producing news stories about Rio/2016 Paralympic Games. This research was qualitative, descriptive, exploratory and inspired by some characteristics of newsmaking studies. We interviewed 15 journalists and editors from distinct Brazilian media groups and newspapers who covered that mega sporting event. Definitions and delimitations of journalistic activity guided by commercial issues, such as time and space constraints for interviewing athletes and occasional difficulty to access local sports idols for news coverage directed to specific locations, indicate that the breadth and complexity of the information collected by journalists to produce news is restricted when no one holds broadcasting rights.

Resumen: El objetivo de la investigación fue caracterizar influencias de la posesión de los derechos de imagen y transmisión en el proceso de producción de noticias sobre los Juegos Paralímpicos Rio/2016. Esta investigación fue de cuño cualitativo, descriptivo y exploratorio y se inspiró en algunas características de los estudios de newsmaking. Se ha entrevistado a 15 periodistas y editores de diferentes medios y periódicos del país que realizaron la cobertura del megaevento deportivo. Las definiciones y delimitaciones del quehacer periodístico pautadas por las cuestiones comerciales, como por ejemplo los límites de tiempo y espacio para entrevistar a los atletas y, a veces, la dificultad de acceder a los ídolos deportivos regionales para la cobertura noticiosa dirigida a localidades específicas, indican que, cuando no se poseen los derechos de transmisión, se restringe la amplitud y la complejidad de las informaciones recogidas por los periodistas para la producción de las noticias.
* Universidade Federal de Mato Grosso do Sul. Campo Grande, MS Brasil.

E-mail:

silvan.menezes@ufms.br

** Universidad CEU Cardenal Herrera. Valencia, Espanha.

E-mail:

pepesolves@gmail.com

*** Universidade Federal do Paraná. Curitiba, PR, Brasil.

E-mail:

desouzdo@yahoo.com

Recebido em: 19-02-2019 Aprovado em: 12-02-2020 Publicado em: 23-02-2020 


\section{INTRODUÇÃO}

O Comitê Paralímpico Brasileiro (CPB), responsável burocrático, comercial e social pelo desenvolvimento do esporte paraolímpico no país, desde a sua criação em 1995, concentra esforços em uma política de investimento nas ações de comunicação e mídia em torno do esporte para pessoas com deficiência, principalmente na divulgação dos Jogos Paralímpicos (JP) em âmbito nacional. Todos os presidentes que estiveram à frente da entidade até hoje consideraram a aproximação com a mídia fundamental para a popularização do esporte paraolímpico no país e também para a atração de possíveis patrocinadores que subsidiassem financeiramente esta manifestação esportiva (MIRANDA, 2011).

Com base nos estudos de Pires (2006) sobre os estágios do processo de midiatização do esporte, podemos afirmar que a versão paraolímpica estaria amadurecendo a transição do primeiro para o segundo estágio deste processo. Segundo o autor, a primeira etapa ocorre através da utilização que a mídia faz dele, transmitindo e noticiando, para expor marcas de produtos diversos e assim angariar cotas publicitárias. O segundo estágio deste processo, por sua vez, se configura quando a própria manifestação do esporte vira o produto, negociado e vendido para a mídia através dos direitos de transmissão. É quando a mídia passa de intérprete ou informante e se torna coautora do fenômeno esportivo, bem como quando os estádios viram sets de televisão (SPÀ, 1999).

Após 20 anos do início da política de comunicação desenvolvida pelo CPB de aproximação com a mídia, o esporte paraolímpico tem ocupado espaço em noticiários esportivos do país ${ }^{1}$, tendo marcas associadas que o patrocinam e buscam publicidade através desta manifestação esportiva. Apesar disso, somente em 2012 as Organizações Globo compraram os direitos de transmissão dos Jogos Paralímpicos para transmiti-los em seu canal fechado da rede por assinatura (SporTV). Para 2016, as Organizações Globo novamente adquiriram os direitos de transmissão dos JP, desta vez tanto para a tv aberta como para a fechada, e os sublicenciaram para a Tv Brasil no caso da primeira ${ }^{2}$. Na televisão fechada, o Sportv teve o maior índice de audiência da sua história durante a transmissão da cerimônia de abertura dos JP/2016 ${ }^{3}$. Medições de audiências televisivas por todo o mundo apontaram um recorde de assistência para esta edição de 2016 dos JP4.

Neste contexto de estreitamento das relações entre o esporte paraolímpico e a mídia, faz-se importante entender: de que forma a negociação e a detenção exclusiva dos direitos de transmissão e de imagem do esporte paraolímpico interferem no trabalho jornalístico de produção e veiculação da informação sobre esta manifestação esportiva? A partir desta problemática, o objetivo da investigação foi caracterizar influências da detenção dos direitos de imagem e transmissão no

\footnotetext{
1 Um exemplo de espaço no noticiário do país é o site globoesporte.com, que criou uma seção específica para notícias sobre a temática. Disponível em: http://globoesporte.globo.com/paralimpiadas/. Acesso em: 21 dez. 2017.

2 O contrato de sublicenciamento está disponível em: http://www.ebc.com.br/institucional/sites/ institucional/files/ atoms/files/contrato_1042-2015__globosat_programadora_Itda.pdf> Acesso em: 31 out. 2017.

3 Os dados do Ibope estão disponíveis em: http://natelinha.uol.com.br/noticias/2016/09/12/sportv-2-atinge-maioraudiencia-da-sua-historia-com-abertura-da-paraolimpiada-102033.php. Acesso em: 21 dez. 2017.

4 Os dados oficiais veiculados pelo IPC estão disponíveis em: https://www.paralympic.org/news/rio-2016-paralympicssmash-all-tv-viewing-records. Acesso em: 21 dez. 2017.
} 
processo de produção de notícias sobre os Jogos Paralímpicos Rio/2016 realizado por jornalistas esportivos.

\section{PERCURSOS E ESTRATÉGIAS METODOLÓGICAS}

Esta pesquisa foi de cunho qualitativo, descritivo, exploratório e se inspirou em algumas características dos estudos de newsmaking. Os estudos de newsmaking, segundo Wolf (1987; 2001), têm em seu rito metodológico o acompanhamento do fazer jornalístico no interior de uma redação, tendo as entrevistas como uma estratégia complementar de busca e produção de dados. Porém, por buscarmos uma variedade de possibilidades e modos de agir da cultura jornalística em relação ao esporte paraolímpico, adotando a estratégia de variação máxima de Patton (2001), tornou-se inviável acompanhar e estar presente, em tempo real, em diferentes redações de jornais durante a cobertura dos JP 2016. Neste sentido, como forma de colher o maior número de relatos de diferentes redações, adotamos a entrevista semiestruturada como procedimento principal para a produção dos dados junto aos interlocutores do estudo.

Realizamos 15 entrevistas, que ocorreram no período entre 02/10/2016 e 21/11/2016, com duração média de uma hora. Deste total, oito entrevistas aconteceram presencialmente e as outras sete ocorreram por webconferência, por meio do software Skype.

Foram entrevistados jornalistas e editores de diferentes grupos de mídia e jornais do país que realizaram a cobertura dos JP Rio/2016. Entre eles estiveram profissionais que trabalharam para mídias com circulação local/regional e mídias com alcance nacional. Selecionamos oito profissionais de quatro mídias de circulação local/regional, quatro de duas mídias com alcance nacional e também três assessores de comunicação do CPB. No decorrer do trabalho os grupos de mídia/jornais foram denominados como "Regional" quando de alcance local, sendo numerados de um a quatro, ou "Nacional", numerados de um a três (neste grupo está incluído o CPB). Por exemplo, "Regional 1", "Regional 2", "Nacional 1" e "Nacional 2".

Para apresentação dos dados mantivemos o anonimato dos interlocutores do estudo e preservamos as identidades deles utilizando nomes fictícios ${ }^{5}$. $\mathrm{Na}$ tabela 1 - a seguir - apresentamos um perfil de cada um dos editores e jornalistas participantes de acordo com as funções que exerceram, o alcance das mídias em que trabalharam, a posição em que estiveram durante a cobertura do megaevento e também se as empresas possuíam ou não os direitos de imagem e transmissão dos JP/2016. 
Tabela 1 - Apresentação e descrição dos interlocutores do estudo

\begin{tabular}{c|c|c|c|c|c}
\hline Número & Nome & Função & Mídia & Posição & $\begin{array}{c}\text { Detentor de } \\
\text { direitos }\end{array}$ \\
\hline 1 & Fred & Editor & Regional 1 & Da redação & Não \\
\hline 2 & Luiz & Jornalista & Regional 1 & Da redação & Não \\
\hline 3 & Rodrigo & Editor & Regional 2 & Da redação & Não \\
\hline 4 & Sara & Jornalista & Regional 2 & Da redação & Não \\
\hline 5 & Mariana & Editora & Regional 3 & Da redação & Não \\
\hline 6 & Antônio & Jornalista & Regional 3 & In loco & Não \\
\hline 7 & Ícaro & Jornalista & Regional 3 & Da redação & Não \\
\hline 8 & Philipe & JOrnalista & Regional 4 & Da redação & Não \\
\hline 9 & Fernando & Editor & Nacional 1 & $\ln$ loco & Sim \\
\hline 10 & André & Jornalista & Nacional 1 & $\ln$ loco & Sim \\
\hline 11 & Vinicius & Jornalista & Nacional 1 & $\ln$ loco & Sim \\
\hline 12 & Francisco & Jornalista & Nacional 2 & $\ln$ loco & Não \\
\hline 13 & Martins & Editor & Nacional 3 & $\ln$ loco & Sim \\
\hline 14 & Jaciara & Jornalista & Nacional 3 & $\ln$ loco & Sim \\
\hline 15 & Jorge & Jornalista & Nacional 3 & $\ln$ loco & Sim \\
\hline
\end{tabular}

Fonte: os autores

Na organização e análise dos dados recolhidos utilizamos a técnica de análise de conteúdo (BARDIN, 2009). Organizamos esse conteúdo apresentado na fala dos interlocutores de acordo com os elementos basilares que compõem o processo de produção de notícias, ou seja, a condição do trabalho, a rotina produtiva, os critérios de noticiabilidade e os valores-notícia. Portanto, apresentamos os dados (unidades de registro da pesquisa) em suas relações e intersecções com as características e influências dos direitos de transmissão e de imagem na cobertura dos JP de 2016. Realizamos tal análise explorando as diferentes perspectivas e as contraposições evidenciadas pelos interlocutores do estudo.

\section{OS ACHADOS DA PESQUISA}

Um primeiro elemento que podemos destacar da influência dos direitos de transmissão no processo de produção de notícias sobre os JP/2016 foi a restrição espacial e temporal imposta ao trabalho de parte dos jornalistas que estavam cobrindo o dia-a-dia da competição. De acordo com depoimentos dos jornalistas, havia benefícios para aqueles profissionais que compunham as equipes das mídias detentoras dos direitos, tanto no que se refere à posição dos mesmos nas zonas de entrevistas - chamadas zonas mistas - como com relação ao tempo que eles tinham para conversar com os atletas.

A fala do jornalista André, que compunha a equipe de uma das emissoras detentoras dos direitos de transmissão no Brasil, em contraponto com a fala do jornalista Antonio, que era o único jornalista de uma mídia escrita regional fazendo a cobertura in loco, são representativas da distinção espacial e temporal existente na logística de organização da produção de notícias durante os JP. 
ANDRÉ: Tinham duas zonas mistas, era interessante isso. Uma era a zona mista de quem ia entrar ao vivo pós-prova [...] a gente era a única emissora brasileira lá [...] E tinha a zona mista, que aí tinha um monte de emissoras espalhadas, que não tinham acesso à piscina, onde os atletas passavam.

ANTONIO: Para as emissoras de TV, Globo, Ebc, enfim, que consumiam muito tempo do atleta lá, ele ficava quarenta minutos as vezes lá na TV até chegar no impresso, nos sites. As vezes ele chegava ali e já tava cansado de responder as mesmas coisas, ou já tinha que ir pro cerimonial de medalha, daí era muito pouco tempo ali pra gente assim.

A fala do jornalista Antonio expõe o desequilíbrio da distribuição do tempo do atleta para conceder entrevistas aos jornalistas. Entre uma série de questões passíveis de problematização a partir dos relatos acima, a primeira que destacamos é a distinção entre o espaço-tempo destinado às mídias televisivas e o que restava para as demais mídias - impressa e sites. As primeiras estabelecem contratos comerciais com as instituições representantes do esporte e, neste caso, com as dos JP, tornando-se sócias do negócio (BETTI, 1998; SPÀ, 1999; 2007; PIRES, 2002). As demais mídias, mesmo podendo contribuir para a ampliação do alcance social e da visibilidade que o megaevento viria a ter através da veiculação de notícias nos espaços e regiões do país por onde circulam - seja em âmbito nacional ou local -, gerando assim mais audiência e atraindo mais cotas publicitárias, elas tornam-se marginais no processo de produção de notícias por não entrarem diretamente com dinheiro no negócio midiático-esportivo.

A priorização jornalística para as televisões no contexto dos JP/2016 reforça o quanto que o telespetáculo esportivo (BETTI, 1998) continua sendo hegemônico como objeto da simbiose entre mídia e esporte. Mesmo com o advento da internet e das mídias sociais digitais, e mesmo os JP sendo um fenômeno esportivo contemporâneo (MARQUES; GUTIERREZ, 2014), concomitante à cultura de convergência dos meios (JENKINS, 2009), o poder econômico e simbólico da televisão no âmbito da cultura esportiva aparenta ter ganho somente algumas ramificações a mais. O exemplo desta situação ratifica a tese de Duarte (2011), de que a internet nesta versão 2.0 nada mais é do que uma capilarização dos mecanismos tradicionais de dominação da indústria cultural, que tem como uma das principais representantes da sua operação a televisão.

A marginalização espaço-temporal gerada pela priorização comercial que adentrou as fronteiras da produção jornalística sobre os JP, conforme ressaltado pelos interlocutores André e Antonio, implica também no empobrecimento dos relatos e informações esportivas passíveis de serem produzidas e posteriormente veiculadas nas notícias. Desta forma, um megaevento esportivo como os JP, que se constitui em uma oportunidade de valorização e reconhecimento da experiência global da prática esportiva por pessoas com deficiência (MARQUES, 2016), ao invés de ter múltiplos canais midiáticos para dar voz aos atletas, acaba se restringindo aos canais de comunicação esportiva que pagam pelos direitos de transmissão.

O desequilíbrio de espaço de produção indicado pelos jornalistas do nosso estudo é mais um indício do que tem sido apontado por Spà (2007) e Sanfelice (2010) como o predomínio da lógica financeira-esportiva-midiática-comercial sobre a lógica esportiva no relacionamento entre a mídia e o esporte. Na correlação de forças existente entre ambos, os interesses de grupos de comunicação de massa 
hegemônicos são atendidos pelas instituições gestoras do esporte, que thes concedem tais privilégios por meio dos contratos de direitos de transmissão. Nesse sentido, a busca por um possível equilíbrio nesta relação é de responsabilidade das entidades do sistema esportivo (SPÀ, 2007), e no caso do nosso estudo, portanto, é dos Comitês internacionais e nacionais do esporte paraolímpico.

Existe, no entanto, uma dificuldade na obtenção deste equilíbrio uma vez que as entidades gestoras do esporte, inclusive as do esporte paraolímpico, têm interesses nas verbas oriundas dos direitos exclusivos de transmissão, pois são parte orçamentária importante na sua gestão e na transformação das variadas manifestações esportivas em espetáculo (PAYNE, 2006; PIRES, 2002; PRONI, 2008). Pelo lado do jornalismo, vale ressaltar que o furo de notícias e a exclusividade da informação são mecanismos de distinção e valorização na cultura midiática e jornalística (TRAVANCAS, 2010). Esses são motivos que ajudam a explicar o alto investimento financeiro da indústria da mídia na compra destes direitos e, como consequência, a exigência dela pelo caráter exclusivo das transmissões e imagens esportivas. Não sendo assim, dificilmente se investiria tantos recursos na midiatização do esporte.

Além dos fatores jornalísticos e esportivos impactados pelas determinações comerciais dos direitos de transmissão, o depoimento de Antonio também evidencia como esta relação de propriedade/sociedade da mídia com o esporte pode ser exaustiva para o atleta. Ele passa a ter outras responsabilidades - neste caso midiáticas e comerciais - que vão além dos elementos competitivos, do esforço físico e mental que um megaevento esportivo como os JP exige. A percepção revelada pelo jornalista sobre o tempo dedicado pelo atleta para a mídia, principalmente para a televisiva, logo após o desgaste intenso da competição, reitera como são reificadas e mercadorizadas as dimensões humanas e esportivas daqueles que são os protagonistas do telespetáculo esportivo. Como afirma Marin (2008, p. 86), "a vitrine televisiva retoma o que existe na atividade humana de vívido e de fluido, embala com estratégias triviais e fascinantes, e oferece como mercadoria".

As formas como se estabelecem as relações entre a indústria midiática e as instituições esportivas também podem ocorrer de maneira diversa, sem desgastar o relacionamento interpessoal entre os profissionais ali envolvidos - jornalistas e atletas. Uma situação mencionada pelo interlocutor André revela um nível de compreensão em relação ao estado psicológico e físico do atleta no momento pós-prova. Porém, esta mesma situação também é reveladora de como o atleta, ainda que descontente com os resultados da competição, retorna para conceder entrevistas ao menos para a mídia detentora dos direitos de transmissão.

\begin{abstract}
ANDRÉ: Primeira prova do André Brasil ele saiu muito bravo da água, ele ficou em quarto lugar sem medalha e era uma prova que ele era bicampeão. Então ele pediu pra não falar, eu entendi, beleza. Aí perguntaram pra mim no ponto: pô e o André? Eu disse: pô, ele pediu pra não falar. Tá bom, segue o jogo. Deu um tempo, ele voltou ali pra falar. Quero dizer, ali o acesso era muito fácil, o cara sabia onde encontrar a gente também.
\end{abstract}

A situação explanada pelo jornalista denota respeito por parte dele com relação ao momento esportivo do atleta. Ainda que no primeiro instante tenha 
ocorrido uma cobrança dos editores pela entrevista ao vivo com o atleta no momento pós-prova, aparentemente houve uma compreensão da equipe jornalística quanto ao descontentamento do nadador diante do resultado final.

O retorno do atleta André para conversar com o jornalista depois de algum tempo, a facilidade do acesso do atleta ao jornalista e o fato de o nadador saber exatamente onde encontrar o profissional para conceder a entrevista, indicam que podem existir diferentes elementos que intermediam a relação entre jornalistas e atletas. Os atletas paraolímpicos sabem da importância da mídia para a promoção, valorização e reconhecimento deles e do esporte paraolímpico perante a sociedade (FIGUEIREDO, 2019; MARQUES et al., 2014; 2015). Eles - bem como as instituições que gerenciam o esporte paraolímpico - também sabem da importância da mídia no processo de construção e divulgação de uma imagem positiva deles para o mercado investidor (CEGALINI; ROCCO JUNIOR, 2019). Considerando que o jornalismo esportivo é um importante interlocutor da construção social do esporte (BORELLI; FAUSTO NETO, 2002), é possível que o atleta tenha retornado para conversar com o jornalista para aproveitar a oportunidade de preservar e promover a sua imagem e a imagem do esporte paraolímpico.

Para alguns jornalistas, o esporte paraolímpico e os atletas paraolímpicos são uma espécie de "sub-representação esportiva", pois possuem baixa popularidade e supostamente têm pouco teor competitivo e atlético (GOLDEN, 2003; SOLVES et al., 2018). Para atletas paraolímpicos, por sua vez, existe um despreparo de parte dos jornalistas esportivos que cobrem o esporte para pessoas com deficiência. Segundo atletas de alto rendimento brasileiros, normalmente os repórteres desenvolvem o trabalho jornalístico neste contexto de modo passageiro, a curto prazo, e de forma despreparada, pois não acompanham o processo de desenvolvimento esportivo ao longo dos ciclos dos JP (FIGUEIREDO, 2019). Talvez o atleta André tenha retornado também por reconhecer o valor da oportunidade ímpar que Ihe havia sido ofertada para relatar a sua experiência esportiva.

Outro dado que poderia ser utilizado para justificar a pouca valorização ou desrespeito pelo espaço-tempo da produção jornalística de um jornalista é o fato dele fazer parte de uma mídia escrita regional, sobretudo por ser um veículo de mídia com alcance e circulação em menor escala. Todavia, a fala de Francisco, jornalista de uma mídia nacional, conforme apresentaremos a seguir, também reforça o incômodo com os benefícios e privilégios que são concedidos à mídia televisiva detentora de direitos comerciais com o esporte.

FRANCISCO: Há um claro benefício à imprensa televisionada, sobretudo as grandes emissoras, sobretudo a Tv Globo e a Sportv [...] Entendo que são detentoras de direitos e não sei o que, mas eu imagino e acho que o CPB nesse momento tinha uma falha de... uma falha de entendimento de cobertura jornalística. Acho que por mais que você tenha que atender a Tv e tal, tal, tal, eu acho que é um tanto aético você dar prioridade o tempo todo para as TVs.

O comentário de Francisco sobre o acesso privilegiado das emissoras de televisão aos atletas remonta a problemática da operação comercial da indústria cultural no âmbito do esporte paraolímpico. O relato demonstra não só como a peça de entretenimento permeia e influencia a dimensão da informação jornalística no seu 
produto final, a notícia. Esta situação é exemplar da produção do infotenimento - do embaralhamento das fronteiras entre informação e entretenimento (GOMES, 2008). Ou seja, temos, aqui, um exemplo de como os interesses comerciais dos negócios esportivos se instalam no início e no meio do processo de produção noticiosa do mundo do esporte. As estratégias da indústria midiático-esportiva, deste modo, demonstram estar operando na própria organização do trabalho investigativo dos jornalistas. Mesmo fazendo parte da equipe jornalística de uma mídia escrita, impressa e online, de alcance nacional, a insatisfação apresentada pelo jornalista, como ele mesmo menciona, está relacionada aos limites éticos de equilíbrio de distribuição e organização dos espaços e tempos do processo de produção jornalística no âmbito dos JP.

Os jornalistas se mostraram insatisfeitos com as benesses concedidas aos detentores de direitos, pois isto se relaciona também com possíveis prejuízos que a organização espacial e temporal das zonas de entrevistas causa para o trabalho deles. A dificuldade de acessar e, por vezes, de entrevistar os atletas paraolímpicos na zona mista durante os JP implicou diretamente no desenvolvimento do trabalho que eles realizaram ou que gostariam de realizar na cobertura do megaevento. Os atletas são as fontes primárias do jornalista esportivo. Ao enfrentarem dificuldade ou serem impedidos de acessar os atletas paraolímpicos, o trabalho jornalístico destes profissionais se vê ameaçado. A ação jornalística no esporte, apesar de ter a possibilidade de incorporar fatores específicos do universo esportivo que ajudam a compor as notícias, como a ficha técnica dos jogos e competições, precisa seguir também regras gerais do jornalismo, entre as quais estão as entrevistas com as fontes (BORELLI; FAUSTO NETO, 2002).

A assessora de comunicação do CPB, Jaciara, que também trabalhou na assessoria do Comitê Olímpico Brasileiro (COB) para os Jogos Olímpicos (JO) de 2016, afirma que esta é uma questão existente no âmbito de praticamente todos os eventos esportivos.

JACIARA: Você tem a questão de que tem televisões que são detentoras de direitos de filmagem, os atletas chegam na zona mista e passam primeiro por elas, e muitas vezes essas televisões seguram os atletas muito tempo e aí na hora que eles passam pela imprensa escrita, a imprensa escrita já está com o prazo de fechamento estourando [...] Mas assim, isso não foi exclusividade dos Paralímpicos. Aconteceu com os Paralímpicos, aconteceu com os Olímpicos, aconteceu em Londres, aconteceu em Toronto.

Pires (2006, p. 6) argumenta que a espetacularização do esporte como entretenimento "refere-se à indiferenciação proposital de que se revestem as suas diversas manifestações, mediadas pela televisão, e a impossibilidade de subsistirem alternativas que não se submetam a esta uniformização". O autor ainda complementa que, "não que as diferentes modalidades estejam se tornando assemelhadas, mas sim que o processo de produção, venda e consumo do espetáculo esportivo segue uma lógica análoga, baseando-se em idênticos procedimentos técnicos e iguais interesses comerciais" (PIRES, 2006, p. 6). Podemos inferir a partir da fala de nossos interlocutores, que este mesmo procedimento se estendeu e controlou o funcionamento do trabalho jornalístico na dimensão da informação esportiva durante 
a cobertura dos JP. Ou seja, identificamos no presente estudo, por parte do sistema midiático-esportivo paraolímpico, a reprodução de processos técnicos e comerciais de outros sistemas esportivos, como por exemplo, o olímpico (PAYNE, 2006; PRONI, 2008), o da FIFA 6 (BORGES, 2018) e de clubes de futebol (BORGES, 2019).

Outra questão que apareceu como problemática no interior da relação jornalística entre mídia e esporte frente aos contratos dos direitos de transmissão foi a restrição da atuação de jornalistas de veículos locais/regionais no acesso à informação e/ou aos atletas, ao tentarem realizar a cobertura direto da redação. Segundo relato do editor Rodrigo, de uma mídia que não se credenciou para atuar nos JP e que não enviou jornalistas para a cobertura in loco devido a restrições orçamentárias da empresa, os direitos de imagem e de transmissão funcionaram como um bloqueio de contato com os atletas durante os dias de competição e assim reduziram também o volume de informação que chegava à redação para a produção de notícias.

RODRIGO: Mesmo assim, daqui combatemos esse problema, entrevistando vários catarinenses que foram... tiveram sucesso na paralimpíada, que não foram muitos. Santa Catarina não tem muita tradição, mas os que tiveram sucesso a gente cobriu, certo? Cobriu daqui, entrevistando daqui, inclusive com sérias dificuldades. Na natação tivemos campeões que você mandava uma mensagem, ou tentava acessar e eles não podiam te responder por ordem do $\mathrm{COB}^{7}$, só quem estivesse cobrindo. Então a gente teve um delay nessa cobertura, só pôde entrevistar muito depois, aí já tinha perdido o feat, sabe?

Neste caso se evidencia mais uma vez como os modos de negociação dos direitos de transmissão atravessaram as condições da produção jornalística sobre o esporte paraolímpico. Novamente a exclusividade dos direitos para a mídia televisiva e as restrições para as demais mídias impediram, sobretudo, o acesso de jornalistas de meios de comunicação impressos aos atletas. Ou seja, os direitos funcionaram como um bloqueio para o contato de alguns deles com aquelas que são, segundo Borelli e Fausto Neto (2002), as fontes primárias da informação esportiva. Este modo de ação e organização da indústria midiático-esportiva na compra e negociação dos direitos de transmissão representa, nos termos de Martín-Barbero (2009), a conversão da liberdade de imprensa em livre concorrência de mercado e, consequentemente, em hegemonia e monopolização da comunicação esportiva.

Além do bloqueio ao trabalho jornalístico, o formato de negociação dos direitos de transmissão inibiu também a possibilidade de se dar voz aos atletas para contarem um pouco das suas experiências esportivas para o público das suas respectivas localidades. Importa destacar que para uma mídia escrita e regional não se tem a opção de concorrer e acessar a disputa pelos direitos de imagem e transmissão, visto que eles são negociados a níveis de nação e, normalmente, são restritos aos veículos audiovisuais como internet e televisão. Nesse sentido, a única alternativa para a mídia impressa e online é quando a mesma se constitui como parte do conglomerado midiático que adquire os direitos de transmissão do megaevento.

\footnotetext{
6 Federação Internacional de Futebol.

7 Quando se refere ao COB, o interlocutor estaria se referindo ao CPB, confundindo as siglas das instituições gestoras do esporte olímpico e paraolímpico.
} 
A formação dos conglomerados midiáticos é um fenômeno da globalização econômica, propulsor da mundialização da cultura, não sendo diferente com as manifestações culturais do esporte, desde o final do século $X X$ até os dias atuais (PIRES, 2002). Deste modo, prioriza-se interesses simbólicos e comerciais transnacionais, em detrimento das interações e demandas das diferentes culturas e localidades.

A restrição do acesso aos atletas, inclusive por vias telefônicas, se apresenta como uma determinação não democrática das relações comerciais que circundam o esporte e o esporte paraolímpico. O caso citado pelo editor do jornal impresso demonstra, por exemplo, como os termos contratuais dos direitos de transmissão entre os conglomerados da mídia e as instituições esportivas podem inibir o processo de produção jornalística de um jornal local durante uma cobertura de grande escala tal como a dos JP. Estes limites impostos ao processo de produção jornalística local identificados nos dados do nosso estudo, podem ser um dos aspectos motivadores da falta de visibilidade e de exposição jornalística alegada por competidores nacionais e locais do esporte paraolímpico brasileiro no estudo de Marques et al. (2014).

A dialética global-local, por exemplo, é uma operação simbólica comumente utilizada pelo jornalismo esportivo impresso e local para atrair a atenção dos seus leitores (SANTOS; MEZZAROBA; SOUZA, 2017). Especialmente em coberturas jornalísticas de megaeventos esportivos que possuem dimensões globais e que, por conta disso, podem se configurar como fatos distanciados de determinadas localidades, a dialética global-local funciona estrategicamente na aproximação do público com algo que Ihes é familiar. O discurso midiático-esportivo tende a se constituir através de uma narrativa que une elementos contextuais do fato esportivo global, com elementos do contexto sociocultural por onde a mídia circula. Estes elementos de composição da narrativa podem ser verbais ou não verbais, diretos ou indiretos. Normalmente a dialética global-local é mobilizada no discurso jornalístico através dos atletas que representam a determinada localidade onde o veículo midiático está inserido, trabalhando assim com uma cobertura informativa voltada para os ícones esportivos daquele universo específico (BITENCOURT et al., 2005; PIRES et al., 2008).

Outra influência dos direitos de transmissão na cobertura dos JP que ressaltamos é a intervenção da Olympic Broadcasting Services (OBS) no trabalho jornalístico de produção e veiculação de informação. A OBS é uma empresa vinculada ao Comitê Olímpico Internacional (COI), responsável pela negociação dos direitos de transmissão tanto dos $\mathrm{JO}$, como dos JP, com grupos midiáticos de todo o mundo. Ela é também geradora das imagens oficiais veiculadas destes megaeventos esportivos.

Os negócios de marketing e direitos de transmissão dos JP são gerenciados pela OBS desde o início dos anos 2000, através de contrato firmado entre o International Paralympic Committee (IPC - Comitê Paralímpico Internacional, em português) e o COI. Esta associação da instituição paraolímpica com os negócios olímpicos garantiu estabilidade financeira para o IPC (HOWE, 2008; PURDUE; HOWE, 2012), pois com isso os JP foram incluídos nas obrigatoriedades estruturais e logísticas para as cidades postulantes à realização dos JO. A partir desta aproximação com o COI, o 
IPC também passou a desfrutar da visibilidade midiática e das cotas publicitárias que a sua correlata olímpica já possuía no mercado. O acordo com o COI, no entanto, prevê que esta entidade tenha direito a uma porcentagem de lucro em todos os contratos publicitários que o IPC venha a firmar. Ele também estabelece que toda a geração de imagens das transmissões dos JP seja de controle da OBS (HOWE, 2008; PURDUE; HOWE, 2012).

A relação contratual entre COI e IPC, segundo Howe (2008) e Purdue e Howe (2012), trouxe implicações para o discurso educativo de valorização e reconhecimento dos atletas com deficiência por parte do movimento paraolímpico, pois toda a sua autonomia midiática de veiculação foi retirada. De acordo com os autores, a correlação dos olímpicos com os paraolímpicos provocou a marginalização destes últimos e os colocou em um segundo patamar dos atletas de alto rendimento, prejudicando assim o potencial de ampliação da cultura esportiva e inclusiva em nível internacional por meio dos JP.

Verificamos junto aos assessores do CPB - conforme relato a seguir - a subserviência comunicativa da referida instituição aos ditames e lógicas de produção da OBS. Um exemplo disso foi a falta de atenção e de garantia de transmissão de modalidades em determinados momentos do cotidiano da competição por parte da OBS, ainda que algumas delas possuíssem fortes interesses nacionais do Brasil na disputa dos jogos. São situações prejudiciais, como previsto, para a expansão cultural e para o discurso educativo do movimento paraolímpico (HOWE, 2008; PURDUE; HOWE, 2012), que demonstram também, tal como descrito por Spà (2007), a fragilidade e pouca influência das instituições esportivas (paraolímpicas, neste caso) sobre as decisões midiáticas e comunicativas.

\begin{abstract}
MARTINS: [...] Então, durante os Jogos, acho que o exemplo mais marcante foi o do vôlei sentado, que começou a ser transmitido a partir da semifinal por uma certa pressão aí das emissoras brasileiras, da Tv Brasil, da Globosat, para que... você tinha o Brasil na semifinal tanto do masculino, como do feminino, então para que isso... para que eles mostrassem. E teve um caso que eu tinha falado com você que era o do tênis de mesa né!? Você tinha a semifinal da Bruna Alexandre, brasileira jogando com a polonesa que é o principal, senão o maior, um dos maiores nomes do tênis de mesa paralímpico e... elas estavam jogando e o tênis de mesa só tinha o sinal de uma mesa e não tinha jogo na mesa naquela hora. Então assim, ficou muito claro assim, que era um certo descaso... não sei se chegaria a tanto, mas acho que faltou se informar melhor, faltou se aproximar mais dos interesses do país sede.
\end{abstract}

A fala do interlocutor revela os impactos comunicativos gerados ao esporte paraolímpico pela centralização do poder midiático na OBS e pelos modos de negociação de direitos de imagem e transmissão realizados pela empresa olímpica. É uma maneira de trabalho que prioriza o lucro e empobrece a experiência de apropriação cultural do esporte paraolímpico, bem como limita a sua expansão pelas diferentes ambiências e localidades. Como educar o público internacional de que é possível jogar vôlei ou tênis de mesa em alto nível, sendo uma pessoa com algum tipo de comprometimento motor, sem que as instituições midiáticas veiculem estas modalidades massivamente em uma oportunidade como os JP? O discurso midiático é um dos principais responsáveis pela formação e veiculação dos símbolos, valores e códigos constituintes da cultura esportiva (PIRES, 2002). 
A restrição da transmissão do vôlei sentado ao momento das semifinais e a falha na veiculação da semifinal do tênis de mesa feminino, onde competia uma atleta brasileira com expectativa de medalha, é mais uma evidência de que a possibilidade educativa e formativa de uma cultura esportiva paraolímpica por meio dos JP está à mercê dos interesses comerciais da empresa olímpica, a OBS. Este exemplo reforça a tese de que as negociações dos direitos de transmissão e de imagem permeiam o processo comunicativo do esporte em todas as suas dimensões, ou seja, do entretenimento ao jornalismo. Não obstante, isto ratifica a tese da predominância da lógica financeira-esportiva-midiática-comercial sobre a lógica esportiva no relacionamento entre a mídia e o esporte, bem como reitera a responsabilidade das instituições esportivas em retomarem o equilíbrio desta relação, preservando a dimensão do fenômeno esportivo (SPÀ, 2007).

De acordo com os interlocutores deste estudo, a OBS estabelece algumas obrigatoriedades jornalísticas de cobertura para os detentores de direitos de transmissão. De acordo com depoimentos do editor da "Nacional 1" e também de um dos jornalistas que participou da cobertura, havia a exigência, por parte do IPC e da OBS, de se ter a transmissão ao vivo de ao menos uma hora diária de competição e também uma hora por dia, no mínimo, de telejornalismo dedicado aos JP.

\begin{abstract}
FERNANDO: Inicialmente existia um compromisso da "Nacional 1", compromisso contratual, de ter uma hora ao vivo por dia e uma hora de jornalismo por dia, juntando os 11 dias de competição daria 44 horas... não, daria 22 horas de compromisso que a gente tinha que falar de paralimpíada. Nós botamos ao vivo mais de 110 horas. Então assim, a gente cumpriu e cumpriu bem com o compromisso que tinha que ser cumprido.
\end{abstract}

VINICIUS: Havia uma obrigação no contrato de se transmitir uma hora por dia ao vivo, e fazer pelo menos uma hora de programação sobre os Jogos Paralímpicos. Houve mais né? Porque houve interesse da empresa em fazer uma cobertura bem mais ampla.

Em primeiro lugar, destacamos o interesse da instituição midiática que ambos os jornalistas representam, em veicular um volume maior de horas dos JP, levando ao ar cerca de cinco vezes a mais do tempo mínimo previsto em contrato. Todavia, tal previsão mínima de horas de cobertura representa, mais uma vez, a superficialidade de espaço midiático-esportivo exigido, por parte das entidades gestoras, aos detentores de direitos sobre um megaevento que envolve mais de vinte modalidades em disputa, mais de quatro mil atletas competindo, mais de cem nações ali representadas e grande volume de dinheiro público e privado investido. Se considerarmos os onze dias de competição dos JP e as cerca de dezesseis horas de disputas diárias simultâneas, nas diferentes modalidades que compõem o programa do megaevento, onze horas de cobertura jornalística corresponde a $6,25 \%$ do tempo total do acontecimento esportivo.

Ou seja, na relação comercial entre instituição midiática e esportiva no âmbito do esporte paraolímpico, fica aparente que a primeira investe com lucro garantido das cotas publicitárias, enquanto a segunda investe com risco potencial de ter mais de $90 \%$ da manifestação esportiva invisibilizada, com informação jornalística limitada. Este é um retrato do desequilíbrio entre os campos da mídia e do esporte (SANFELICE, 2010), agora exemplificado no caso paraolímpico. É também mais um 
indício do prejuízo midiático e comunicacional desta manifestação esportiva, gerado pela falta de responsabilidade, que segundo Spà (2007), as instituições gestoras devem ter na preservação da autonomia do campo esportivo frente a outros campos como o midiático.

\section{CONSIDERAÇÕES FINAIS}

Verificamos que as regras de benefícios e prioridades jornalísticas às empresas detentoras dos direitos de imagem e transmissão no processo de produção de notícias sobre os JP/2016 geraram prejuízos à veiculação informativa acerca da referida manifestação esportiva. As definições e delimitações do fazer jornalístico pautadas, predominantemente, por questões comerciais, restringem a amplitude e a complexidade das informações a serem recolhidas pelos jornalistas para a produção das notícias, o que por sua vez prejudica a qualidade das informações que chegam ao público. Assim, por conta dos grandes interesses comerciais envolvidos e pela monopolização midiática permitida pelos gestores esportivos na negociação dos direitos de transmissão, o esporte paraolímpico sofre de intensa fragmentação e empobrecimento em relação a sua expansão na cultura esportiva global.

Podemos considerar, portanto, que a relação comercial da mídia com o esporte está gerando o aprofundamento do processo de semiformação cultural a respeito do fenômeno esportivo, neste caso, em específico, do esporte paraolímpico. A semiformação esportiva tinha como principal característica, até então, a substituição da experiência formativa da prática do esporte pelo consumo dele via mediação midiática (PIRES, 2002, 2006). No entanto, a partir dos exemplos da cobertura jornalística dos JP do Rio/2016, podemos afirmar que temos agora também um processo de restrição à produção informativa sobre o fenômeno esportivo que conduz, direta ou indiretamente, à transformação da própria informação jornalística em objeto/meio de propaganda midiática do esporte. Estamos visualizando, assim, a intensificação do processo de mercadorização e espetacularização do esporte e do esporte paraolímpico através do condicionamento da cobertura jornalística sobre o fenômeno esportivo pela via da informação-mercadoria.

Os resultados deste estudo indicam para a necessidade das instituições esportivas (paraolímpicas) travarem uma luta nas negociações com a mídia, de modo a mudar a lógica predominante. Esta deve ser uma batalha por garantias contratuais de uma veiculação comunicativa da cultura esportiva, que envolva, por exemplo, a diversidade de modalidades e de pessoas com vários níveis e tipos de deficiência praticantes do esporte paraolímpico. Esta batalha deve também estabelecer limites nestes contratos em relação à diferenciação entre a dimensão da transmissão das peças de entretenimento esportivo e a produção jornalística. Ou seja, as instituições esportivas devem definir mais claramente os direitos midiáticos sobre a veiculação das competições em si, sem que isto seja um gerador de privilégios espaçotemporais para a dimensão do jornalismo, permitindo, por exemplo, a possibilidade de realização de entrevistas e de acesso aos atletas por parte dos jornalistas, sejam eles de empresas detentoras dos direitos ou não. 
Estudos dedicados a analisar criticamente documentos existentes sobre as negociações entre mídia e esporte podem contribuir para o aprofundamento do tema em questão. Temos indícios de ser inviável a existência do espetáculo do esporte de alto rendimento, assim como o esporte paraolímpico, tal como é hoje, sem o processo de midiatização e mercadorização pelo qual ele passa desde a segunda metade do século XX. O alto custo tecnológico e científico para o desenvolvimento permanente de atletas, dos equipamentos, dos materiais e dos espaços esportivos, que protagonizam os feitos esportivos espetaculares e ajudam a fidelizar os espectadores ao redor do mundo, não permite que se abdique do volumoso recurso dos direitos de transmissão. Deste modo, para além de questionar a validade ou não destes direitos como objeto da simbiose entre a mídia e o esporte, o nosso estudo indica a necessidade de um maior aprofundamento na investigação dos modos como este fenômeno se estabelece e na busca por alternativas para a gestão do esporte de modo a preservá-lo como elemento da cultura contemporânea.

\section{REFERÊNCIAS}

BARDIN, Laurence. Análise de Conteúdo. Lisboa: Edições 70, 2009.

BETTI, Mauro. Janela de vidro: esporte, televisão e educação física. Campinas: Papirus, 1998.

BITENCOURT, Fernando Gonçalves et al. Ritual olímpico e os mitos da modernidade: implicações midiáticas na dialética universal / local. Pensar a Prática, v. 8, n. 1, p. 21-36, 2005.

BORELLI, Viviane; FAUSTO NETO, Antonio. Jornalismo esportivo como construção.

Cadernos de Comunicação, n. 7, p. 61-74, 2002.

BORGES, Fernando Vannier. Ao vivo direto da Rússia: a Copa do Mundo formatada para televisão. Fulia, v. 3, n. 2, p. 88-108, 2018.

BORGES, Fernando Vannier. Os clubes de futebol e novas formas de produzir a informação desportiva. Mediapolis, n. 8, p. 119-133, 2019.

CEGALINI, Vinicius Lordello; ROCCO JUNIOR, Ary. Comunicação corporativa e gerenciamento de reputação em organizações esportivas. C\&S - São Bernardo do Campo, v. 41, n. 2, p. 85-117, 2019.

DUARTE, Rodrigo. Industria cultural 2.0. Constelaciones: Revista de Teoría Crítica, n. 3, p. 90-117, 2011.

FIGUEIREDO, Tatiane Hilgemberg. A voz dos atletas: mídia e Jogos Paralímpicos no Brasil. Mediapolis, v. 8, p. 85-99, 2019.

GOLDEN, Anne V.. An Analysis of the Dissimilar Coverage of the 2002 Olympics and Paralympics: Frenzied Pack Journalism versus the Empty Press Room. Disability Studies Quarterly, v. 23, n. 3/4, p. 1689-1699, 2003. 
GOMES, Itania Maria Mota. O embaralhamento de fronteiras entre informação e entretenimento e a consideração do jornalismo como processo cultural e histórico. In: DUARTE, Elizabeth Bastos; CASTRO, Maria Lilia Dias de (eds.). Em torno das mídias: práticas e ambiências. Porto Alegre: Sulina, 2008. p. 95-112.

HOWE, P. David. From Inside the Newsroom: Paralympic Media and the 'Production' of Elite Disability. International Review for the Sociology of Sport, v. 43, n. 2, p. 135-150, 2008.

JENKINS, Henry. Cultura da Convergência. São Paulo: Aleph, 2009.

MARIN, Elizara Carolina. O espetáculo esportivo no contexto da mundialização do entretenimento midiático. Revista Brasileira de Ciências do Esporte, v. 30, n. 1, p. 75-89, 2008.

MARQUES, Renato Francisco Rodrigues. et al. A abordagem midiática sobre o esporte paralímpico : o ponto de vista de atletas brasileiros. Movimento, v. 20, n. 3, p. 989-1015, 2014.

MARQUES, Renato Francisco Rodrigues. et al. A abordagem mediática sobre o desporto paralímpico : perspetivas de atletas portugueses. Motricidade, v. 11, p. 123-147, 2015.

MARQUES, Renato Francisco Rodrigues. A contribuição dos Jogos Paralímpicos para a promoção da inclusão social : o discurso midiático como um obstáculo. Revista Brasileira de Educação Física e Esporte, n. 108, p. 87-96, 2016.

MARQUES, Renato Francisco Rodrigues; GUTIERREZ, Gustavo Luiz. O esporte paralímpico no Brasil: profissionalismo, administração e classificação de atletas. São Paulo: Phorte, 2014.

MARTÍN-BARBERO, Jesús. Dos meios às mediações: comunicação, cultura e hegemonia. Rio de Janeiro: Editora UFRJ, 2009.

MIRANDA, Tatiane Jacusiel. Comitê Paralímpico Brasileiro: 15 anos de história. Campinas: Universidade Estadual de Campinas, 2011.

PATTON, Michael Quinn. Qualitative evaluation and research methods. 3. ed. Newbury Park: SAGE, 2001.

PAYNE, Michael. A virada olímpica: como os Jogos Olímpicos tornaram-se a marca mais valorizada do mundo. Rio de Janeiro: Casa da Palavra, 2006.

PIRES, Giovani De Lorenzi. A Educação Física e o discurso midiático: abordagem crítico-emancipatória. ljuí: Unijuí, 2002.

PIRES, Giovani De Lorenzi et al. Jogos Olímpicos e a dialética global-local: os catarinenses em Atenas / 2004 na mídia impressa regional. In: SANFELICE, Gustavo; MYSKIW, Mauro (eds.). Mídia e Esporte: Temas Contemporâneos. Novo Hamburgo: Feevale, 2008. p. 65-90.

PIRES, Giovani De Lorenzi. Mídia, Esporte e llusão. Fiesla 2006, Fórum Internacional de Esporte e Lazer - SESC, p. 1-11, 2006. Disponível em: http://www.labomidia.ufsc.br/ index.php/acesso-aberto/publicacoes/publicacoes-2006/doc download/198-esporte-midia-eilusao. Acesso em 15 fev. 2020.

PRONI, Marcelo Weishaupt. A reinvenção dos Jogos Olímpicos: um projeto de marketing. Esporte e Sociedade, v. 3, p. 01-35, 2008.

PURDUE, David E. J.; HOWE, P. David. Empower, inspire, achieve: (dis)empowerment and the Paralympic Games. Disability \& Society, v. 7, n. 2, p. 903-916, 2012. 
SANFELICE, Gustavo Roese. Campo midiático e campo esportivo: suas relações e construções simbólicas. Revista Brasileira de Ciências do Esporte, v. 31, n. 2, p. 137153, 3 mar. 2010.

SANTOS, Silvan Menezes dos; MEZZAROBA, Cristiano; SOUZA, Doralice Lange de. Jornalismo esportivo e Infotenimento: a (possível) sobreposição do entretenimento à informação no conteúdo jornalístico do esporte. Corpoconsciência, v. 21, n. 2, p. 93-106, 2017.

SOLVES, Josep et al. Framing the Paralympic Games: A Mixed-Methods Analysis of Spanish Media Coverage of the Beijing 2008 and London 2012 Paralympic Games. Communication and Sport, v. 7, n. 6, p. 729-751, 2018.

SPÀ, Miquel de Moragas. Comunicación y deporte en la era digital: sinergias, contradicciones y responsabilidades educativas. Contratexto, v. 12, p. 73-92, 1999.

SPÀ, Miquel de Moragas. Comunicación y deporte en la era digital. Congreso De La Asociación Española De Investigación Social Aplicada Al Deporte (AEISAD), 9. Anais [...] Las Palmas de Gran Canaria: Centre d'Estudis Olímpics UAB, 2007. Disponível em: http:// olympicstudies.uab.es/pdf/wp107_spa.pdf. Acesso em: 21 dez. 2017.

TRAVANCAS, Isabel. Etnografia da produção jornalística - estudos de caso da imprensa brasileira. Brazilian Journalism Research, v. 6, n. 2, p. 83-102, 2010.

WOLF, Mauro. La investigación de la comunicación de masas: crítica y perspectivas. Barcelona: Paidós Ibérica, 1987.

WOLF, Mauro. Teorias da comunicação. 6. ed. Lisboa: Presença, 2001.

\section{Apoio:}

O presente trabalho foi realizado com apoio da Coordenação de Aperfeiçoamento de Pessoal de Nível Superior -Brasil (CAPES) - Código de Financiamento 001. This study was financed in part by the Coordenação de Aperfeiçoamento de Pessoal de Nível Superior Brasil (CAPES) - Finance Code 001. 